\section{Postoperative narrow complex tachycardia presenting with low cardiac output}

\section{DESCRIPTION}

A 6-month-old child was diagnosed as a case of complete balanced atrioventricular (AV) canal defect and underwent intracardiac repair. His baseline ECG is shown in figure 1. Soon after shifting from the operating room, he developed a narrow complex tachycardia (shown in figure 2) with a rate between 180 and 210 per minute. His inotropic support, which consisted of low-dose intravenous milrinone, was soon stopped. He started to show signs of low cardiac output with hypotension and reduced urine output, despite fair left ventricle (LV) systolic function. The tachycardia was not responsive to beta blockers, direct current (DC) cardioversion

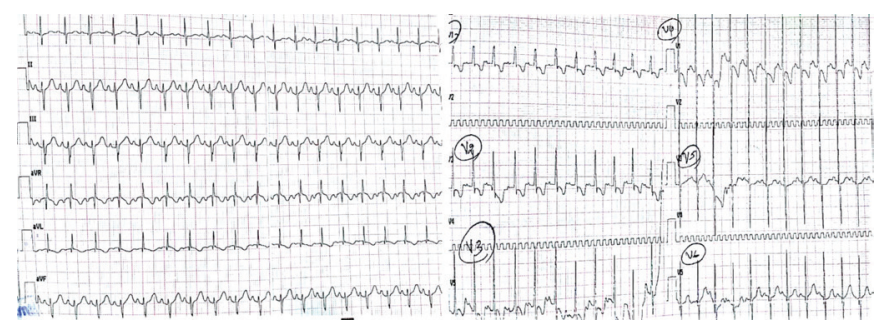

Figure 1 Baseline ECG showing sinus rhythm, left axis deviation, counterclockwise loop and biventricular hypertrophy. and overdrive atrial pacing. He was subsequently started on intravenous amiodarone. He responded to amiodarone with a reduction in the rate to less than 150 per minute but did not revert to sinus rhythm (figure 3 ). With lowered heart rate, he responded to overdrive atrial pacing (figure 4), which led to improvement in clinical status, and was extubated successfully. The child returned to sinus rhythm on the sixth postoperative day and remained so at discharge.

\section{QUESTION}

Which of the following statements about the above illustrated tachycardia is false?

A. AV dissociation is usually present.

B. Most commonly seen after repair of tetralogy of Fallot.

C. Mechanism of arrhythmia is enhanced automaticity.

D. Risk of arrhythmia increases with electrolyte imbalance.

E. Tachycardia usually responds to DC cardioversion.

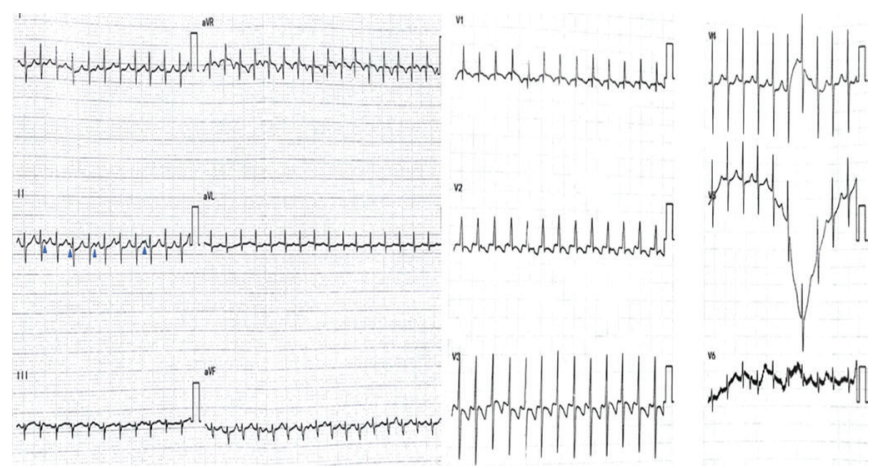

Figure 2 Postoperative ECG.

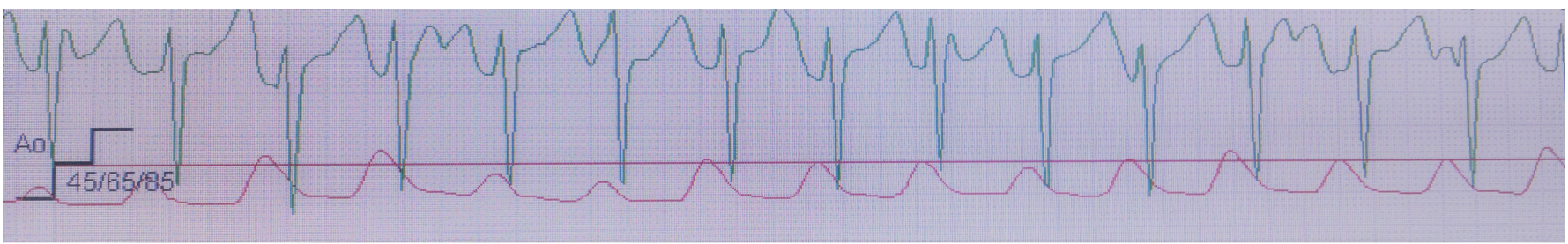

Figure 3 Telemetry recording prior to intravenous amiodarone.

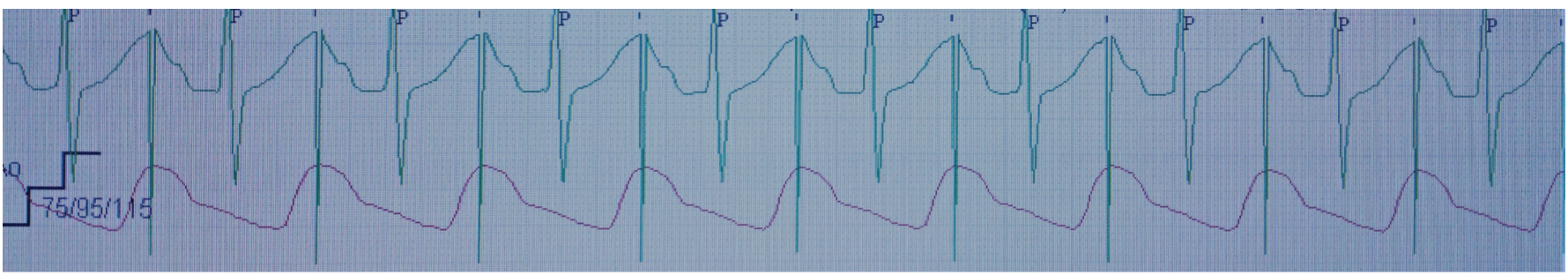

Figure 4 Telemetry recording after amiodarone and on atrial pacing. 


\section{ANSWER: E}

Figure 1 shows a classical ECG of AV canal defect with left axis deviation. Figure 2 shows junctional ectopic tachycardia (JET), usually a self-limiting tachycardia, characterised by AV dissociation ( $p$ waves are marked with blue arrowheads in lead II) and heart rates between 170 and 230 per minute. The mechanism of arrhythmia is proposed to be enhanced automaticity of the bundle of His. ${ }^{1}$ It is most commonly seen after repair of tetralogy of Fallot and also commonly seen after ventricular septal defect (VSD) closure, AV canal defect repair and Fontan operation. Risk factors include younger age at surgery, longer cardiopulmonary bypass time, electrolyte imbalance (hypokalaemia and hypomagnesaemia) and inotrope use (dopamine and milrinone). JET is unresponsive to DC cardioversion. ${ }^{2}$ Amiodarone is the antiarrhythmic of choice and helps in lowering the rate. ${ }^{3}$ Other drugs used in management include propafenone, flecainide and digoxin. After rate control, overdrive atrial pacing may be used to maintain AV synchrony. Radiofrequency ablation and Extracorporeal membrane oxygenation (ECMO) as therapeutic options are limited to refractory cases. Figure 3 illustrates the beat-to-beat variability in pulse waveform during tachycardia because of AV dissociation, which normalised after atrial pacing (figure 4) and re-establishment of AV synchrony.

\section{Priyadarshini Arunakumar, Krishna Kumar Mohanan Nair,} Ajitkumar Valaparambil

Department of Cardiology, Sree Chitra Tirunal Institute for Medical Sciences and Technology, Thiruvananthapuram, India
Correspondence to Dr Priyadarshini Arunakumar, Department of Cardiology, SCTIMST, Trivandrum, KL 695011, India; priya_arun_2000@yahoo.com

Contributors PA: patient management. MKK, AVK: mentoring.

Competing interests None declared.

Patient consent Guardian consent obtained.

Ethics approval SCTIMST Institutional Ethics Committee.

Provenance and peer review Not commissioned; externally peer reviewed.

(c) Article author(s) (or their employer(s) unless otherwise stated in the text of the article) 2017. All rights reserved. No commercial use is permitted unless otherwise expressly granted.

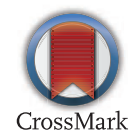

To cite Arunakumar P, Mohanan Nair KK, Valaparambil A. Heart Asia Published Online First: [please include Day Month Year]. doi:10.1136/heartasia-2017-010977

Heart Asia 2017;9:1-2. doi:10.1136/heartasia-2017-010977

\section{REFERENCES}

1 Till JA, Ho SY, Rowland E. Histopathological findings in three children with his bundle tachycardia occurring subsequent to cardiac surgery. Eur Heart $J$ 1992;13:709-12.

2 Villain E, Vetter VL, Garcia JM, et al. Evolving concepts in the management of congenital junctional ectopic tachycardia. A multicenter study. Circulation 1990;81:1544-9.

3 Raja P, Hawker RE, Chaikitpinyo A, et al. Amiodarone management of junctional ectopic tachycardia after cardiac surgery in children. Br Heart J 1994;72:261-5. 